\title{
Non-viral ex vivo therapeutic strategy in chemically derived hepatic progenitor with adenine base editor and prime editor
}

\author{
Yohan Kim, Sangtae Yoon, Myoung-Hoi Kim, Da Hee Hong, Taehun Kim, Jaemin Jeong, Dongho Choi
}

Division of Hepatobiliary, Department of Surgery, Hanyang University College of Medicine, Seoul, Korea

Background: The adenine base editor ( $\mathrm{ABE}$ ) and prime editing converts nucleotide in living cells without double strand DNA breaks. Chemically derived stem/progenitor cells are attracting attention as the most applicable cell sources for clinical trials. Combining these attracting techniques, we show an ex vivo therapeutic strategy to treat hereditary disease.

Methods: We generate chemically derived hepatic progenitors ( $\mathrm{CdHs}$ ) from a tyrosinemia mouse model caused by a mutation in base pair $A$ into $G$, correcting it via $A B E$ and prime editing, and then transplanting it into the model mouse to cure it.

Results: Corrected $\mathrm{CdH}$ s with $\mathrm{ABE}$ repopulated the liver with fumarylacetoacetate hydrolase-positive cells after transplantation and increased survival rate. In addition, the substitution of non-target $\mathrm{A}$ in ABE editing window of the CdHs is reduced after transplantation.

Conclusions: This strategy offers a safer and specific way to apply a base editor to clinical applications.

Corresponding author: Dongho Choi

E-mail: crane87@hanyang.ac.kr

(C) The Korean Society for Transplantation

This is an Open Access article distributed under the terms of the Creative Commons Attribution Non-Commercial License (http://creativecommons.org/licenses/by-nc/4.0/) which permits unrestricted non-commercial use, distribution, and reproduction in any medium, provided the original work is properly cited. 